\title{
Chemical Ecology and Marine BIODIVERSITY: INSIGHTS AND PRODUCTS FROM THE SEA
}

\author{
By Mark E. Hay and William Fenical
}

.. secondary

metabolites .... can

have important com-

plex or indirect

effects that alter

marine biodiversity

on the genetic,

species, and ecosys-

tem levels.
T REMENDOUS ATTENTION has been focused on the loss of, and threats to, terrestrial biodiversity. Until very recently (Norse, 1993), much less attention was devoted to marine biodiversity despite the fact that marine systems are larger, older, have a huge impact on global climate, and support nearly twice as many phyla of animals as do terrestrial systems (see Table 2-2 in Norse, 1993). Our reduced attention to marine biodiversity reflects our relative ignorance of marine systems rather than their lack of importance to humans or to the ecosystem functions on which virtually all terrestrial life depends. Humans have spent thousands of years in intimate association with terrestrial biota, but only a few decades using SCUBA and submersibles to explore the world's oceans. In this article we discuss how chemically mediated interactions affect marine biodiversity and consider the insights that can be gained from understanding the mechanisms involved in these interactions.

Biodiversity is often used incorrectly as a synonym of species diversity; however, biodiversity also encompasses genetic and ecosystem diversity (Norse, 1993). The factors that produce and maintain patterns of biodiversity at these different levels are complex and poorly understood. In this review, we argue that secondary metabolites produced by a variety of marine organisms as defenses against consumers, pathogens, and competitors (Hay and Steinberg. 1992: Paul, 1992) can have important complex or indirect effects that alter marine biodiversity on the genetic, species, and ecosystem levels.

The role of biogenic structural complexity in affecting species diversity has been extensively studied and is broadly appreciated in both marine and terrestrial communities (Ehrlich and Roughgarden,

Mark E. Hay, University of North Carolina at Chapel Hill, Institute of Marine Sciences, Morehead City. NC 28557. USA Phone: 919-726-6841: FAX: 919-726-2426; Internet: seaweed@email.unc.edu; William Fenical. Scripps Institution of Oceanography. University of California at San Diego, La Jolla, CA 92093, USA: Phone: 619-534-2133; FAX: 619-558-3702: Internet: wfenical@ucsd.edu
1987). As examples. kelps form a structural matrix that is critical for nearshore temperate communities, and corals play this same role on tropical reefs. When kelps are removed by storms, El Niño events, overgrazing by sea urchins, or due to anthropogenic stresses, normal ecological processes are altered and the composition and organization of the entire nearshore community can change dramatically (Simenstad et al., 1978: Tegner and Dayton. 1987: Duggins et al., 1989). In a similar way, destruction of tropical corals due to overfishing, storms, and general habitat degradation (e.g.. sedimentation) lessens topographic complexity and turns species-rich coral reefs into algal beds with reduced biodiversity (Hughes, 1994). Biologically produced chemical diversity may play a similar, but unappreciated, role in structuring marine communities and affecting marine biodiversity.

\section{Distribution and Diversity of Novel Secondary Metabolites}

Secondary metabolites (i.e.. unusual compounds that are not involved in primary metabolism) appear to be most common among tropical benthic organisms that are subject to high rates of attack by consumers on coral reefs (Hay and Steinberg, 1992: Paul, 1992; Pawlik, 1993; Bolser and Hay, in press). However, secondary metabolites also play important roles in temperate (Steinberg, 1992) and Antarctic benthic communities (McClintock, 1994), and possibly in pelagic communities worldwide (Huntley et al., 1986; Paerl, 1988).

Seaweeds, sponges, ascidians, soft corals, and other sessile organisms produce a diverse array of novel secondary metabolites (Figs. 1-6) including terpenes, acetogenins, alkaloids, and polyphenolics. Some of these compounds differ fundamentally from terrestrial secondary metabolites in that they are halogenated (Fig. 1, elatol from the red seaweed Laurencia) and often possess chemical structures that are unprecedented among terrestrial organisms (Faulkner, 1994 and reviews cited therein). To date, several thousand marine secondary metabolites have been described, with 


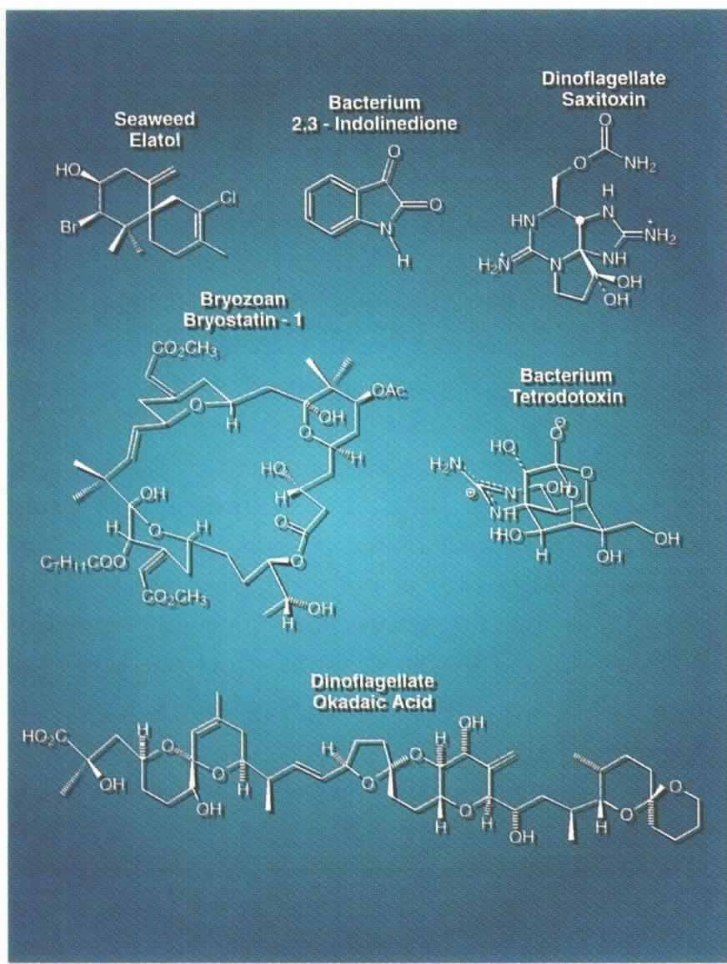

Fig. 1: Examples of marine secondary metabolites.

more being discovered daily. As one example of the chemical variety to be found in marine organisms, members of the red algal genus Laurencia produce an amazing array of complex terpenoids and acetogenins-possibly making it the world's most chemically complex genus. The genus produces over 500 different terpenes representing at least 26 different structural classes, more than 16 of which are novel and found only in Laurencia (Faulkner, 1994 and previous reviews). This type of rich chemical diversity can function as a habitat gradient that promotes the evolution and maintenance of biodiversity through resource or habitat partitioning, specialization of consumers or commensals, and selection for genetic or phenotypic diversity among consumers associated with populations or species that differ chemically. Plant secondary metabolites appear to play this role in terrestrial systems where they are hypothesized to have promoted the tremendous species diversity of herbivorous insects (Strong et al., 1984).

\section{Chemically Mediated Effects on Species Diversity}

The ecology and evolution of marine chemical defenses have been studied most thoroughly for benthic organisms on reefs, with the majority of attention being devoted to defenses against generalist consumers like fishes and urchins (Hay and Steinberg, 1992; Paul, 1992; Bolser and Hay, in press). Once organisms become well defended chemically, they may then become targets of evolutionary opportunity for other potential prey that can avoid their own consumers by association with these chemically noxious hosts. Some examples of how defended organisms enhance the evolution or maintenance of species diversity by producing localized sites of lowered consumer activity or by serving as a source of chemical defenses for other organisms are outlined below.

\section{Associational Refuges: Turning Competitors into Accomplices}

Palatable seaweeds that are usually driven to local extinction by grazers can persist in herbivore-rich communities if they grow on or beneath their herbivore resistant competitors (reviewed by Hay, 1992). The brown seaweed Stypopodium zonale produces cytotoxic compounds that deter feeding by Caribbean reef fishes and urchins. Numerous species of palatable seaweeds are significantly more common near the base of Stypopodium plants than several centimeters away; if the deterrent plant is removed, these more palatable species are rapidly eaten (Littler et al., 1986), lowering local species diversity. When plastic mimics of Stypopodium are placed in the field, they also provide a partial refuge for palatable species, but they are less effective than the real plants, suggesting that associational refuges are generated in part by the physical presence of a nonfood plant, but that the plant's chemical repugnance makes the associational refuge more effective.

In temperate communities, palatable seaweeds can minimize losses to herbivorous fishes and urchins by growing on or near unpalatable seaweeds such as Sargassum filipendula (Hay, 1986; Pfister and Hay, 1988). Growing in close association with these unpalatable competitors depresses the growth of palatable species by as much as $85 \%$, but the associational benefits, in terms of reduced herbivory, can more than offset this competitive cost (Hay, 1986). Thus, palatable species can be dependent on their unpalatable competitors to prevent their exclusion from the community due to herbivory. Correlative and manipulative studies in both field and mesocosm systems indicate that removal of common unpalatable competitors like Sargassum can cause extinction, rather than competitive release, of associated competitors that are more palatable (Hay, 1986). These associational refuges were initially interpreted as arising from simple visual crypsis (Hay, 1986), but more detailed investigations suggest that chemistry plays a significant role (Pfister and Hay, 1988; Wahl and Hay, 1995).

As a final benthic example, up to $18 \%$ of the dry mass of algae in the genus Desmarestia can be sulfuric acid; this concentration is sufficient to quickly kill seaweeds and dissolve barnacles from the rocks when this kelp is deposited in the intertidal by waves (Hay and Fenical, 1988). In Chilean kelp beds heavily grazed by sea urchins,
.. . defended organ-

isms enhance the

evolution or mainte-

nance of species

diversity by produc-

ing localized sites of

lowered consumer

activity . . . 
host organisms

could be coevolved

with certain microbes

because the

microbes produce

compounds that

defend the host from

natural enemies. the palatable kelp Macrocystis cannot successfully colonize unless it invades an area encircled by Desmarestia plants, which appear to act as "acid brooms" that prevent urchins from entering the area (Dayton, 1985). Although planktonic systems are less amenable to field experimentation, similar associational refuges appear to occur in planktonic communities where palatable phytoplankton are grazed less heavily, or not at all, when they are mixed among chemically defended dinoflagellates (Huntley et al., 1986).

The associational escapes discussed above are opportunistic rather than coevolved and, as such, may be used by many organisms in a wide variety of situations (Hay, 1986). There are, however, more intimate chemically mediated associations that may be coevolved. Many marine microbes are predictably associated with specific species of marine macroorganisms. Because of the broad ability of marine microbes to produce bioactive secondary metabolites (Fenical, 1993), many host organisms could be coevolved with certain microbes because the microbes produce compounds that defend the host from natural enemies. As an example. embryos of the shrimp Palaemon macrodactylus are consistently covered by a strain of the bacterium Alteromonas sp. Removal of the bacterium results in $>90 \%$ mortality of the embryos because the bacterium produces 2.3-indolinedione (Fig. 1), which chemically defends the embryos against attack by a pathogenic fungus (Gil-Turnes et al. . 1989). It is possible that many of the ecologically important compounds found in benthic invertebrates could actually be produced by symbiotic microbes. A recent investigation of the symbiotic cyanobacteria from the sponge Dyidea herbacea (Unson and Faulkner, 1993) demonstrated that the sponge metabolites were located exclusively within the microbial symbionts rather than the sponge itself. If symbiotic microbes commonly produce compounds needed by their hosts, then these chemical dependencies would provide an additional interaction facilitating both the evolution and retention of increased species diversity.

In general, the biodiversity and ecological importance (both chemically mediated and otherwise) of marine microbes appears grossly understudied and underappreciated. If molecular biology, improved culture techniques, and investigations of microbial systematics combine to make ecologically realistic investigations of marine microbes more tractable, then future investigations in marine microbiology will undoubtedly make tremendous contributions in both the basic and applied sciences.

\section{Host Chemistry as a Promoter of Consumer Diversity}

Fishes on coral reefs may bite the bottom in excess of 150.000 times/ $/ \mathrm{m}^{2} /$ day (Carpenter, 1986). In these areas, small herbivores like amphipods, poly- chaetes, and crabs (collectively called mesograzers) would have low fitness if they lived on plants that were preferred by fishes because they would become fecal pellets more often than reproductive adults. It was, therefore, hypothesized that selection should favor sedentary mesograzers that could live on and eat chemically defended seaweeds that were avoided by fishes (reviewed by Hay, 1992). In initial tests in temperate North Carolina, it was found that the tube-building amphipod Ampithoe longimana and the tube-building polychaete Platynereis dumerilii preferred to feed on seaweeds that were avoided by fishes. Both of these mesograzers minimized contact with fishes by selectively living on and consuming the brown alga Dictyota menstrualis, which produces diterpene alcohols that deter fish feeding, but that have little effect on feeding by the amphipod or polychaete (Hay, 1991; Duffy and Hay, 1994). In seasons when fishes were common, amphipod species that could not tolerate algal chemical defenses went locally extinct, while the amphipod Ampithoe longimana remained abundant because it used chemically defended algae as safe sites from fish predation (Duffy and Hay, 1994 and references therein)

The hypothesis that small sedentary herbivores could minimize predation by associating with, or specializing on, toxic hosts was tested more broadly using 1) a macrophyte-inhabiting amphipod in the Caribbean: 2) a specialist Caribbean amphipod that eats, and builds a mobile domicile from. a chemically defended alga; and 3) different species of crabs and ascoglossan sea slugs from both the Caribbean and tropical Pacific that each live on and feed from only one species of chemically defended alga (reviewed by Hay. 1992). In all of these cases, mesograzers were stimulated or unaffected by algal compounds that deterred feeding by herbivorous and predatory fishes, and predation on the mesograzers was reduced through their association with these chemically noxious hosts. As one example of how this works (see Hay et al., 1990), the Caribbean amphipod Pseudamphithoides incurvaria lives in a mobile. bivalved domicile that it constructs from the chemically defended seaweed Dictrota bartayresii (Fig. 2A). The diterpene alcohol pachydictyol $A$ that causes fishes to reject the alga as food is the compound that cues domicile building by the amphipod (Fig. 2B). Amphipods in domiciles built from this alga are rejected as food by predatory fishes but are rapidly eaten if they are removed from their domiciles or if they are in domiciles that they have been forced to build from the palatable green seaweed Ulva sp., which is not chemically defended (Fig. 2C).

There are several similar examples showing that seaweeds or sessile invertebrates that evolve effective defenses against reef fishes may become evolutionary targets for specialized mesograzers that can escape or deter their own consumers by 

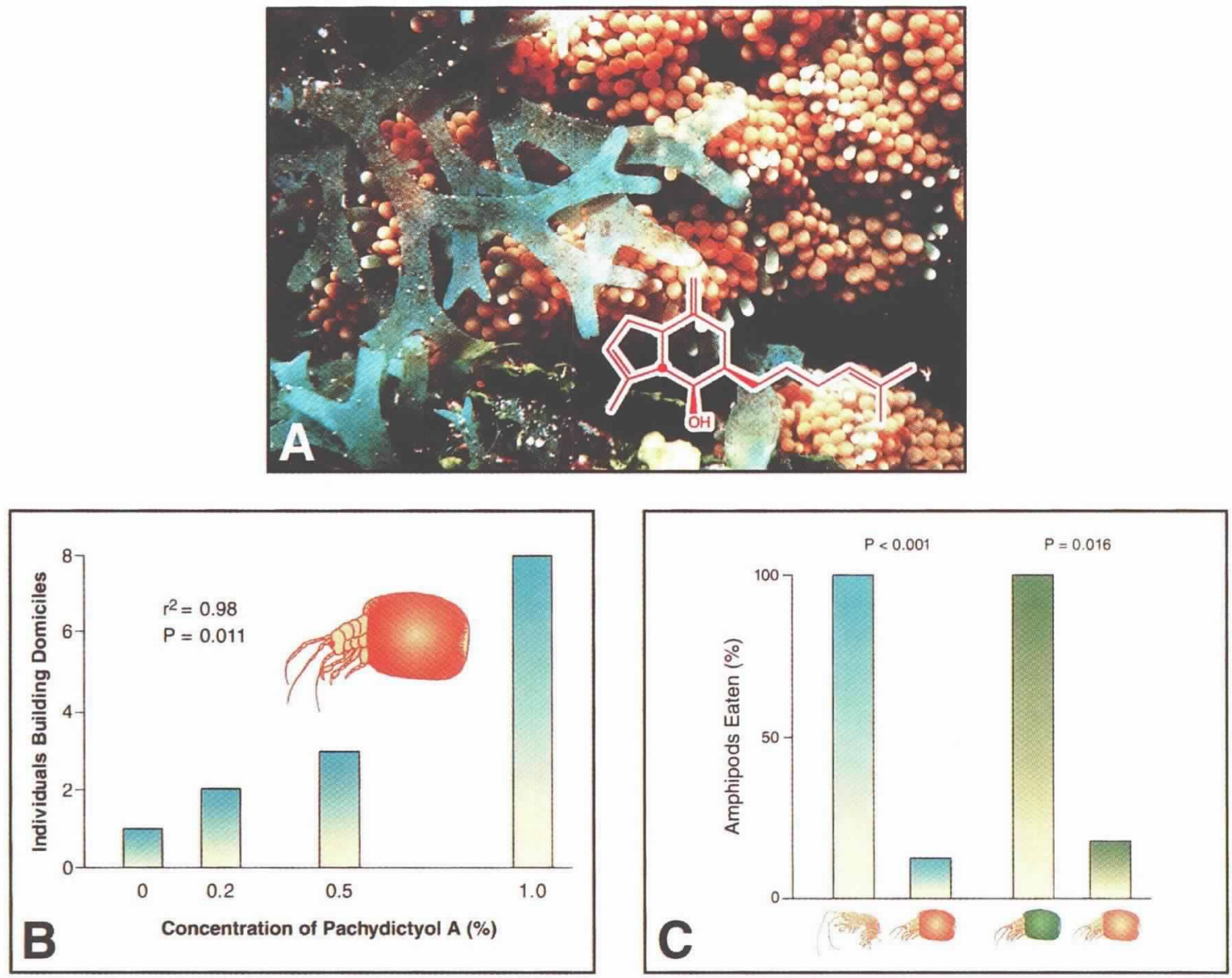

Fig. 2: (A) Dictyota bartayresii and its major secondary metabolite pachydictyol A; (B) Willingness of the amphipod Pseudamphithoides incurvaria to build domiciles from the green seaweed Ulva sp. as a function of pachydictyol A concentrations applied to this alga; (C) Palatability of amphipods to fish as a function of domicile presence and type. Brown domiciles denote ones built from Dictyota; green denotes ones built from the palatable seaweed Ulva (B and $\boldsymbol{C}$ are modified from Hay et al., 1990).

evolving a resistance to these compounds and living on, and feeding from, these chemically rich hosts. Examples (reviewed by Hay, 1992; Paul, 1992; Pawlik, 1993) include specialized crabs (Fig. 3) and ascoglossan gastropods (Fig. 4, A and B) feeding on chemically rich algae, as well as specialized nudibranchs (Fig. 4C) feeding on chemically defended invertebrates such as sponges and ascidians. These specialists escape detection or deter their consumers by living on, feeding from, and, in some cases, morphologically mimicking or sequestering defensive compounds from their toxic hosts. The Spanish dancer nudibranch, Hexabranchus sanguineus (Fig. 4C), provides a well documented example (reviewed in Pawlik, 1993) of sequestration of chemical defenses by a specialist consumer. It feeds on sponges in the genus Halichondria that contain oxazole macrolides that deter feeding by fishes. The nudibranch alters these compounds slightly and concentrates them in its dorsal mantle and in its egg masses, where they serve as defenses against consumers. Concentrations of the macrolides are low in the sponge, higher in the nudibranch, and highest in the egg masses, but even the lowest natural concentrations result in strong suppression of feeding by fish.

Another example of how chemically defended organisms can increase species diversity by providing associational refuges and defenses for both competitors and small specialist consumers involves the chemically defended green alga Chlorodesmis fastigiata on Australia's Great Barrier Reef. This alga was the sole habitat used by one species of crab (Fig. 3), one species of amphipod, three species of ascoglossans, and one species of dorid nudibranch that appeared to feed only on the ascoglossans (Hay et al., 1989). Additionally, on heavily grazed reefs, $\sim 10$ species of seaweeds that normally grow in a wide variety of habitats could be found only within the margins of Chlorodesmis patches (M.E. Hay, personal observation). We also found many species of shelled gastropods sheltering in the alga during the day, but they did not appear to consume Chlorodesmis. It was our impression that removal of this chemi-
. . specialists

escape detection or deter their consumers by living on, . . .

toxic hosts. 

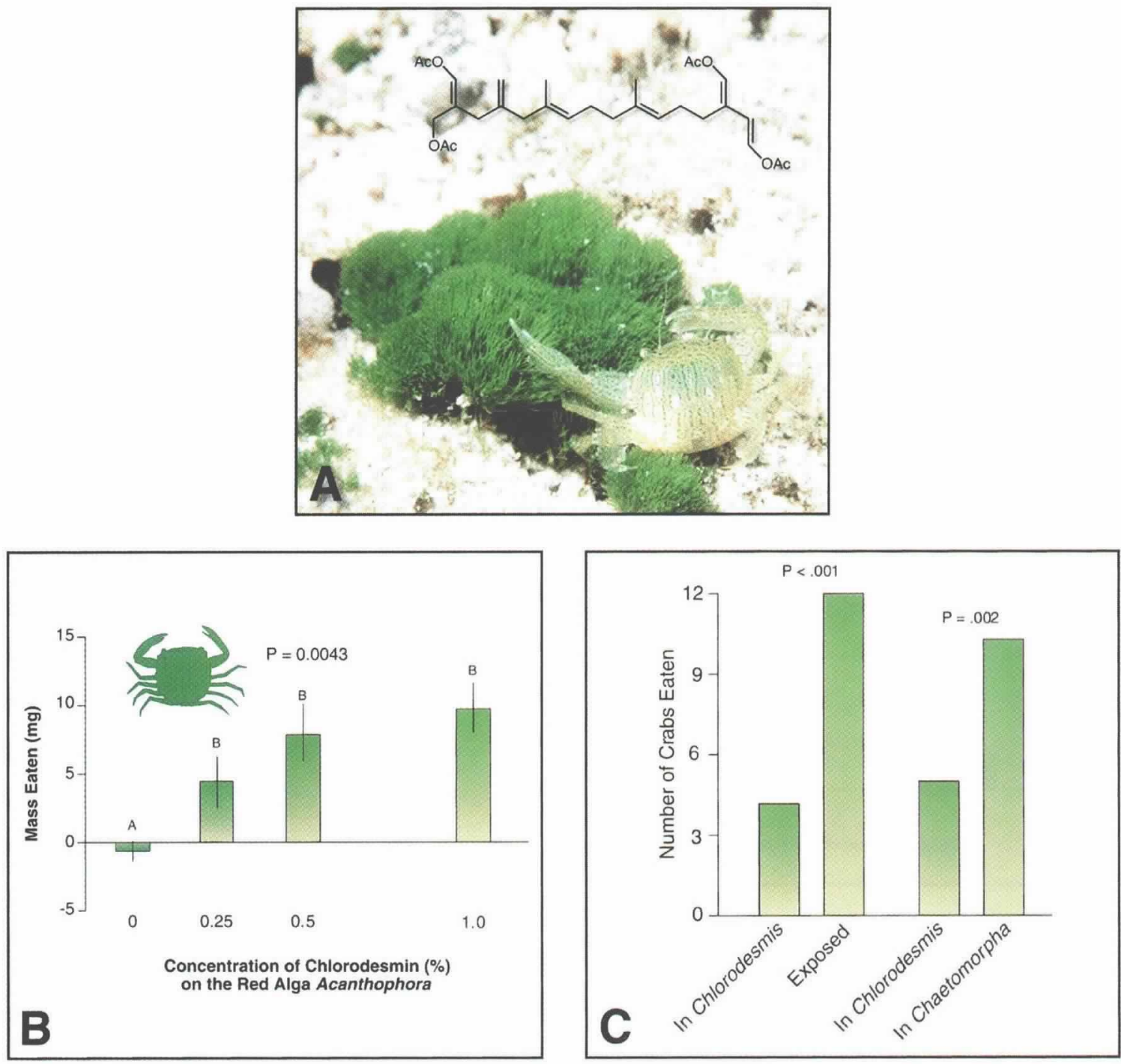

Fig. 3: (A) The specialist crab Caphyra rotundifrons; its host alga Chlorodesmis fastigiata; and the cytotoxic secondary metabolite chlorodesmin, which is produced by the alga; (B) Crab feeding on the red alga Acanthophora spicifera as a function of how much chlorodesmin has been added to the plant; $(\boldsymbol{C})$ Crabs eaten by reef fishes when tethered in versus away from Chlorodesmis and when in the toxic alga Chlorodesmis versus the palatable (to fish), but morphologically similar, seaweed Chaetomorpha sp. (data from Hay et al., 1989).

Chemically mediated and ecosystemwide effects of toxic phytoplankton blooms can be dramatic. . . cally defended alga could have resulted in the loss of $\sim 15-20$ other species that relied on it as a refuge from consumers and, in some cases, as a food. Given the large number of commensals on reefs and their strong association with chemically rich organisms, chemically mediated enhancement of species diversity may be common.

\section{Chemically Mediated Effects on Ecosystems}

Effects of marine secondary metabolites on ecosystems are largely unstudied, but potentially important and numerous. Phenolics from seaweeds can affect humic materials, water color, and chelation of ions in near-shore waters, and when chemically defended organisms die, they may be largely unavailable to detritivores until their bioactive metabolites degrade (see discussion in Hay, 1992). Therefore secondary metabolites could affect characteristics of nearshore water columns, detrital pathways, and thus ecosystemlevel processes such as carbon flow and nutrient cycling.

Chemically mediated and ecosystem-wide effects of toxic phytoplankton blooms (e.g., red tides) can be dramatic (Paerl, 1988), including large scale die-offs of scallops, fishes, and other nontarget organisms, and the resulting loss of thousands of tons of seafood and millions of dollars in fisheries revenues. Along the Gulf Coast of the United States, outbreaks of the toxic dinoflagellate Ptychodiscus brevis have been estimated to kill up to 100 tons of fish per day, and similar ef- 

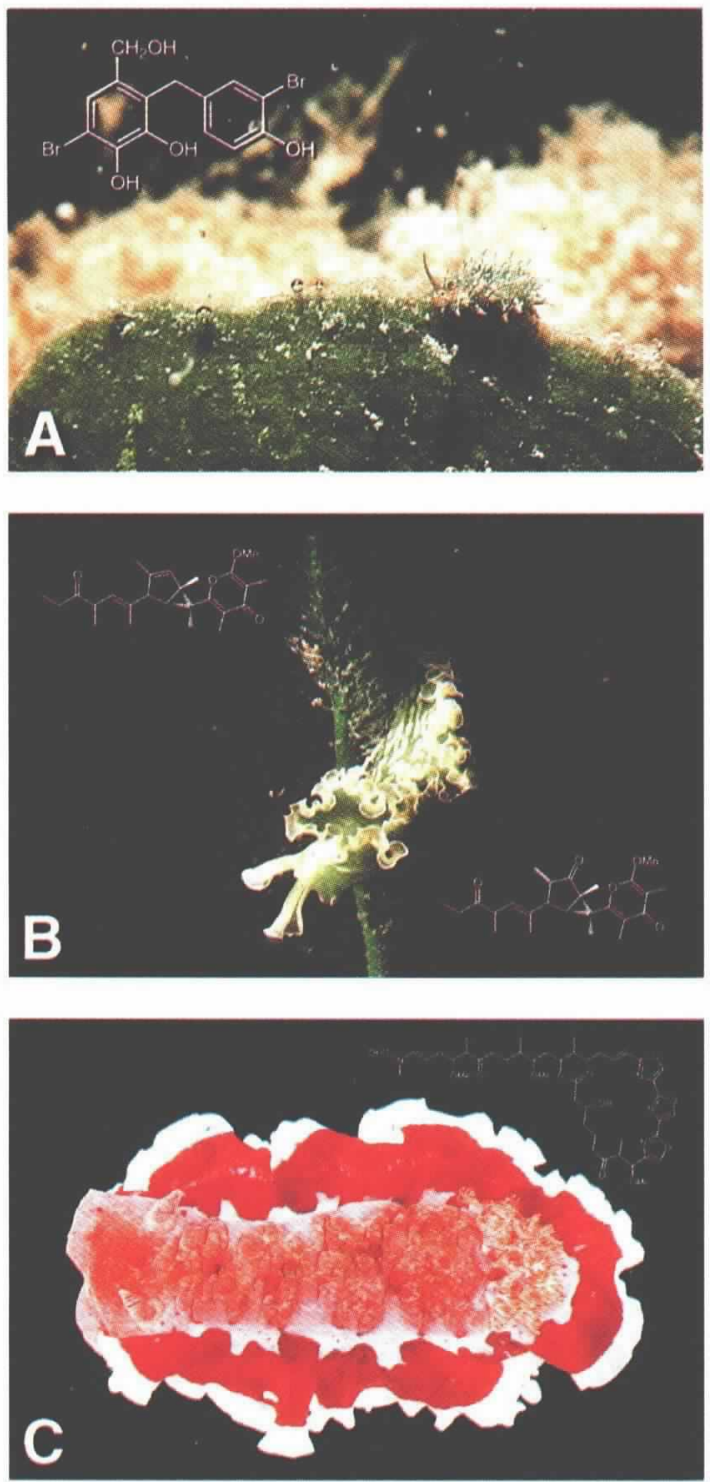

Fig. 4: (A) The ascoglossan sea slug Costasiella oclellifera which sequesters functioning chloroplasts and chemical defenses from its algal host, Avrainvillea longicaulis; $(\boldsymbol{B})$ Tridachia crispata and its deterrent (M.E. Hay and W. Fenical, unpublished observations) chemical defenses, which it appears to manufacture; (C) the Spanish dancer Hexabranchus sanguineus, which specializes on sponges in the genus Halichondria and sequesters defensive oxazole macrolides from these hosts (see Hay 1992 and Pawlik 1993 for references) (photo in $C$ is by J. Pawlik).

fects of dinoflagellate blooms are known for North Carolina, California, Japan, Korea, India, and Sri Lanka (Paerl, 1988).

The paralytic shellfish toxins (see saxitoxin in Fig. 1 as an example) acquired by shellfish through ingestion of dinoflagellates also could have large-scale cascading effects on community structure through their indirect effects on keystone species such as sea otters or other predators, which can play a large part in structuring nearshore temperate ecosystems (Simenstad et al., 1978; Kvitek et al., 1991). Along the west coast of North America, the filter feeding butter clam Saxidomus giganteus is immune to the effects of paralytic shellfish toxins and thus feeds on toxic dinoflagellates and concentrates toxins from these prey. Sea otters, fishes, and birds foraging on these clams are not immune to the toxins. These predators may become sick, or die, if they ingest the most toxinladen portions of clams that have fed on toxic dinoflagellates. Sea otters appear to have been historically absent from areas where dinoflagellate blooms were common, but present in areas where dinoflagellate blooms were rare (Kvitek et al., 1991). It thus appears that dinoflagellate toxins could have affected the regional distribution of sea otters. Because sea otters are such voracious urchin predators, areas with otters have low densities of urchins and abundant kelp beds that attract fishes and pinnipeds, and that provide organic matter that contributes to the growth of a broad range of nearshore species (Simenstad et al., 1978; Duggins et al., 1989). If otters are absent, urchin grazing can destroy kelp beds, create urchin barrens, and dramatically alter ecosystem structure and function. Thus toxins from planktonic dinoflagellates have the potential to substantially alter the structure and productivity of nearshore ecosystems through their indirect effects on keystone consumers like sea otters (Kvitek et al., 1991).

Recent investigators have even suggested that bromoforms, and possibly other haloforms, produced by red and brown marine algae could significantly alter the earth's ozone layer (Barrie $e t$ al., 1988; Weaver, 1988). This hypothesis appears to help explain the springtime depletion of ozone at ground level in a 10-yr data set from Barrow, Alaska, as well as peaks in bromine-containing aerosol observed throughout the Arctic in March and April. If marine secondary metabolites are responsible for an appreciable portion of these changes, then their ecosystem-wide consequences could be considerable and could even include ozone-mediated effects on terrestrial vegetation in coastal areas.

\section{Intraspecific Diversity in the Production of Secondary Metabolites}

Although within-species variance in metabolite production is just beginning to be investigated, variance among different parts of one organism, among different individuals in a population, and among different populations of the same species appears to be considerable for some species (Hay and Steinberg, 1992; Harvell et al., 1993; Bolser and Hay, in press; Cronin and Hay, 1996a,b, in press). Whether this variance is genetic or environmentally controlled is not adequately known, but, given the ecological effects of marine secondary bromoforms,

and possibly other

haloforms, produced

by red and brown

marine algae could

significantly alter the

earth's ozone

layer... . 
metabolites (Paul, 1992), this spatial and temporal variance could affect trophic and competitive interactions in ways that would promote biodiversity at both genetic and species levels by increasing the chemical patchiness of environments (see Bolser and Hay, in press: Cronin and Hay, in press).

As one example with applied repercussions, the bryozoan Bugula neritina contains a group of compounds called the bryostatins. Some of these highly unusual molecules have strong inhibitory activities against human cancer cells. The most important drug from this group is bryostatin I (Fig. 1), which is presently being tested in human clinical trials. Important in this context is the observation that bryostatin 1 is found in animals from only a few of the various sites studied (Pettit. 1991). Thus, if conservation efforts aimed at the preservation of marine biodiversity had succeeded at protecting this species, but not these specific populations, then Bugula's potential contribution to cancer therapy would have been lost. Whether this situation is common or rare for marine organisms cannot be determined because so few studies have been conducted on withinspecies variance in the production of secondary metabolites. However, the omnipresence of vegetative spread and the localized recruitment of larvae and spores for some marine organisms suggest that local adaptation, founder effects, or genetic drift in small populations could result in considerable intraspecific variance in metabolite production for some species.

A recent investigation of geographic variation in seaweed defenses against herbivores demonstrates how profound within-species variance can be (Bolser and Hay, in press). When a large number of related temperate and tropical seaweeds were compared in terms of their palatability to urchins and the deterrency of their chemical extracts. tropical seaweeds were found to be significantly less palatable. However, contrasts within the brown algal genus Dictyota showed dramatic within-species variance that was equivalent to the total variance seen among different species across geographic regions. A shallow water population of Dictyota menstrualis from North Carolina was significantly more palatable than four of the six tropical species of Dictyota. whereas a deeper water population of this same species from the same region was significantly less palatable than four of the six tropical species. Chemical extracts from the shallow water population tended to be less deterrent than extracts from the tropical species, whereas extracts from the deep water population were more deterrent than extracts from the tropical species. If this type of extreme intraspecific variation is common. then conservation efforts focused on biodiversity at the species level may fail to conserve this genetic or phenotypic level of biodiversity.

\section{Intraspecific Variance Versus Uncertain Taxonomy}

As the taxonomy of marine organisms improves, some examples of intraspecific variance in metabolite production will undoubtedly be found to represent between-species rather than within-species patterns. The common red seaweed Laurencia obtusa provides a classic example of chemical variation at the "apparent" species level. By apparent, we mean that many marine organisms, both plants and animals, have been considered to be the same species on the basis of limited morphological and minor anatomical characters. In many cases, these "species" possess significant secondary metabolite diversity within populations, and certainly as a function of distributional range. Laurencia obtusa, for example, has been observed to produce a variety of terpenes and acetogenins representing at least 10 different structural types (Faulkner, 1994 and earlier reviews). Given the observation that many discrete species are chemically homogeneous, at least at the biosynthetic pathway level, these species almost certainly represent species complexes and an underestimation of biodiversity.

The present limits of taxonomic understanding regarding marine organisms clearly compromise our ability to manage, or even define, marine biodiversity (Knowlton et al., 1992: Norse, 1993), and cripple our ability to determine whether differences in the production of secondary metabolites represent intra- or interspecific patterns. Some examples of taxonomic difficulties include the following. 1) Mytilus edulis is one of the world's most studied marine invertebrates and is the focus of a worldwide effort studying geographic patterns in the types and concentrations of pollutants found in its tissues-in 1992. "Mytilus edulis" was discovered to be three separate species. 2) Montastraed annularis is an extensively studied Caribbean coral whose growth and skeletal isotopic ratios form the foundation of numerous studies of paleoceanography, environmental degradation, and global climate change - in 1992, "M. annularis" became recognized as a suite of at least three species. 3) It is not unusual for even very localized studies of marine groups such as gastropods, polychaetes, or flatworms to find hundreds of species, with 50 to $>90 \%$ of these being undescribed (see Knowlton $e t$ al., 1992; Knowlton, 1993; Norse. 1993). If identifying even well studied species is difficult for taxonomic experts, then the ability of natural products chemists and chemical ecologists to accurately identify the organisms (often obscure ones) they are studying will be of considerable concern and will lessen our confidence that we really know which species are producing which compounds.

\section{Insights from, and Pharmaceutical Uses of, Marine Secondary Metabolites}

Terrestrial biodiversity has formed the foundation of the modern pharmaceutical industry: how- 
ever, within the past decade, the enormous biodiversity in the world's oceans also has been recognized. Programs have been established worldwide to evaluate the biomedical utility of marine secondary metabolites (Jones, 1994). Marine metabolites have been developed, or are currently being tested, as antibiotics, pain suppressers, antiinflamatory agents, molecular probes, skin care products, sun screens, and anticancer agents (Fautin, 1988; Attaway and Zaborsky, 1993). Some unique compounds that were unsuitable as drugs, none-theless, became molecular probes yielding new insights into human disease. The classical use of the marine neurotoxins tetrodotoxin and saxitoxin (Fig. 1) as probes of ion channel nerve transmission (Takahashi, 1979) formed the foundation for more recent biomedical uses of marine secondary metabolites. The Conus toxins, small peptides extracted from highly toxic snails of the Indo-Pacific, have recently been shown to elicit amazingly diverse effects, apparently by binding to an array of as yet unknown pharmacological receptors (Myers et al., 1993). These findings may lead to the identification of new behavioral receptors in the brain. A rare sesterterpenoid ( 25 carbon atoms) called manoalide, extracted from a sponge, showed the exceptional ability to selectively bind to phospholipase $A_{2}$, an enzyme central to the onset of inflammatory disease (Potts et al., 1992). As a final example, the cyclic heptapeptide shown in Fig. 5 is one of several marine secondary metabolites that show cytotoxic activity against human cancer cells (Toske and Fenical, 1995).

Although most of the marine secondary metabolites that are presently being explored or developed for commercialization are from macroorganisms, the biodiversity of the world's oceans includes a massive number of marine microbes, with most species probably being un- known. The overall species numbers, chemical diversity, and potential utility of these microbes are difficult to estimate. One such microorganism, the dinoflagellate Prorocentrum lima, was found to produce okadaic acid (Fig. 1), a unique member of a new class of polyethers. Although first being recognized as a causative agent in Diahrretic Shellfish Poisoning (DSP), the compound was later found to possess unprecedented inhibitory properties against phosphatase enzymes, thus leading to its current utilization as an important tool in the study of cell-cycle protein phosphorylation. The four microbial secondary metabolites shown in Fig. 1 provide an example of the extreme chemical diversity represented by marine microbes. To date, the chemical ecology of marine microbes is vastly underinvestigated. We know something of their chemical diversity, but very little about the ecological and evolutionary causes and consequences of these compounds.

Marine biodiversity has led to the derivation of new drugs, particularly compounds to treat diseases that are poorly treated at present. The U.S. National Cancer Institute, in a major program to discover new anticancer agents, has recognized that marine organisms are an exceptional new resource. Of the new substances currently under investigation at NCI, perhaps the most important leads are compounds extracted from marine sponges, bryozoans, soft-corals, worms, and molluscs. Although none has yet to reach the marketplace, several marine drugs are in clinical trials for the treatment of cancer and diseases involving acute inflammation and pain. The plumelike Caribbean sea whip Pseudopterogorgia elisabethae produces the pseudopterosins (Fig. 6), which are antiinflammatory drugs with unprecedented pharmacological mechanisms of action (Look et al., 1986). It appears that the pseudopterosins will, in due time,

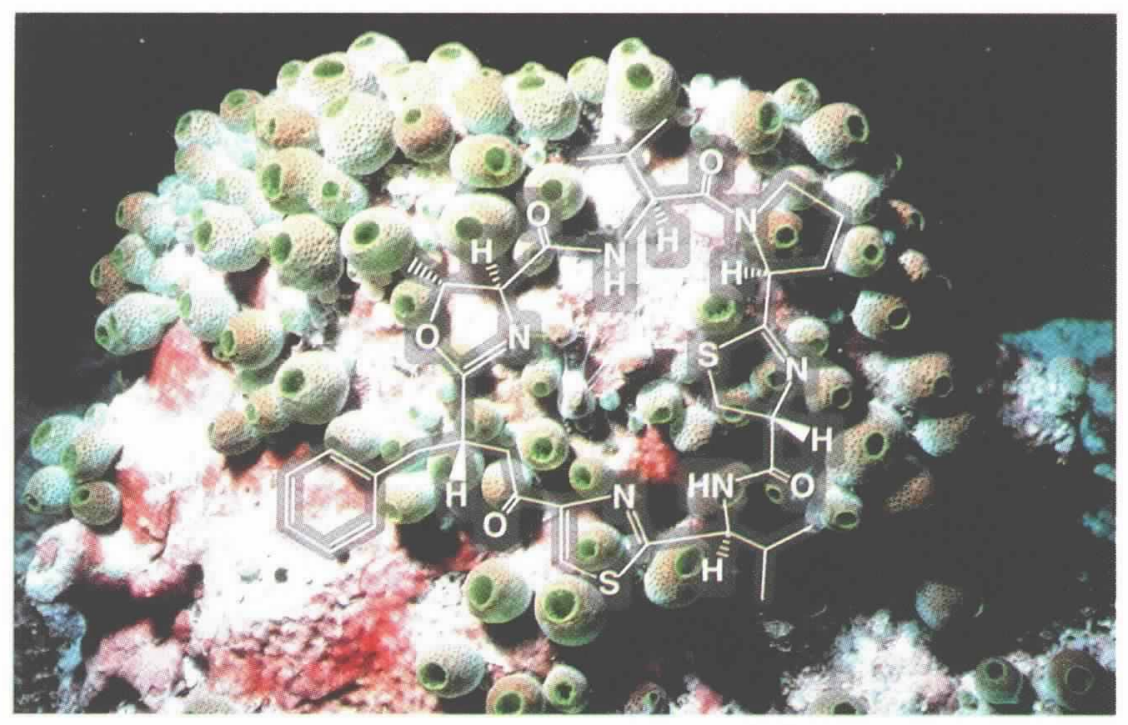

Fig. 5: The tropical tunicate Didemnum molle and the cytotoxic cyclic heptapeptide it produces. 


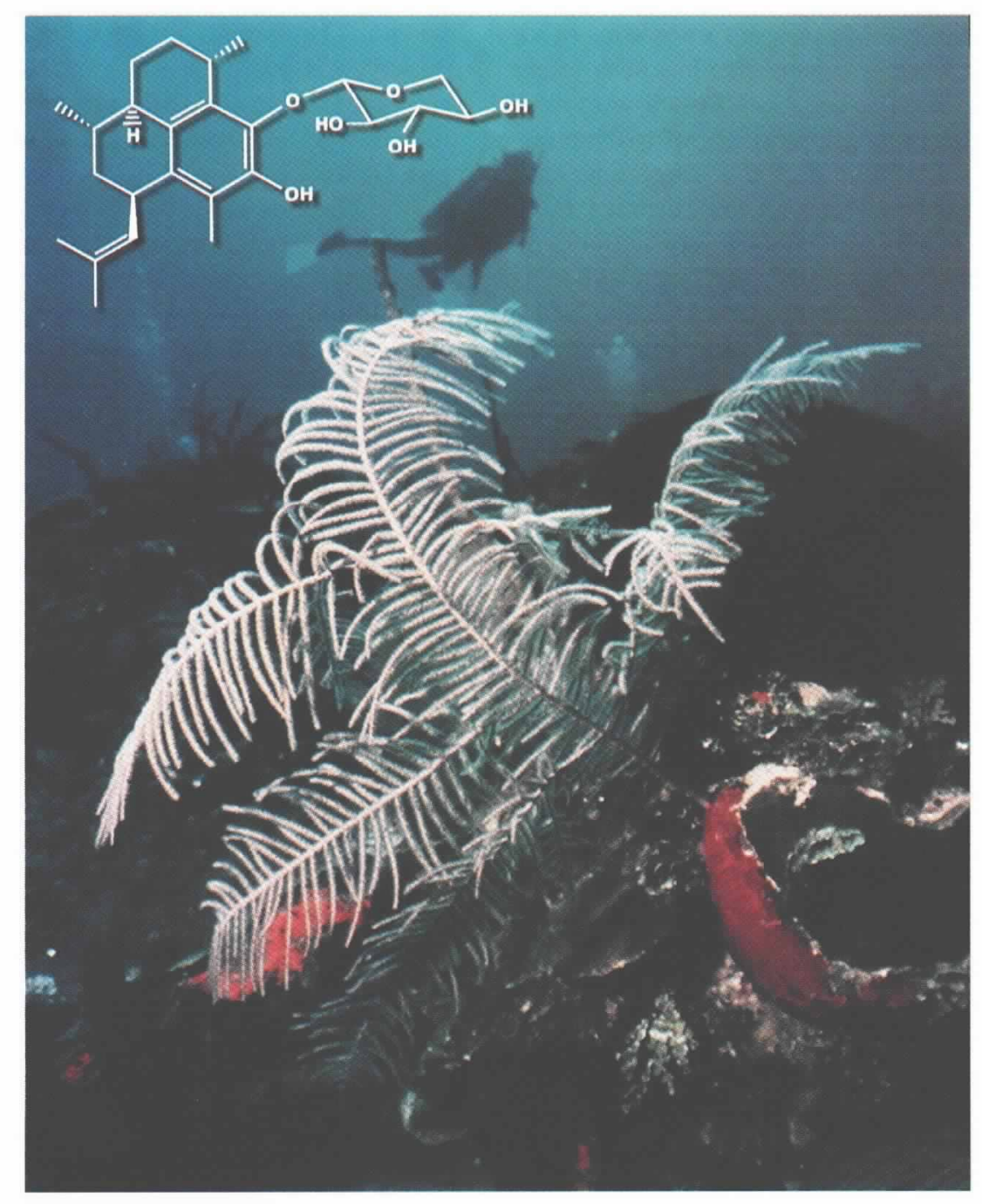

Fig. 6: The sea whip Pseudopterogorgia elisabethae and one of the pseudopterosins it produces.

find application in treating chronic inflammatory diseases such as psoriasis and arthritis.

\section{Conclusions}

Unusual secondary metabolites are produced by a diverse array of marine organisms and appear to function in nature as defenses against consumers, pathogens, and competitors. Although the ecological and evolutionary consequences of these compounds have only recently began to be studied in depth, their effects on marine biodiversity are already being recognized, in that they have consequences for the organization and structure of marine systems at the genetic, population, species, and ecosystem levels. The structural diversity and strong bioactivity of many of these compounds make them excellent candidates for development as pharmaceuticals, agrochemicals, growth regulating substances, and molecular probes. A few compounds have already proven useful in these applications, but many more await discovery.

Although most information on the ecological and evolutionary consequences of marine sec- ondary metabolites comes from investigations of seaweeds and benthic invertebrates in shallow reef communities, similar interactions could be widespread in the plankton (Huntley et al., 1986), among marine microbes (Fenical, 1993), and in deep sea communities. Because hydrothermal vent communities in the deep sea support high densities of potential prey against a broader background of prey scarcity and potential food limitation, they could be somewhat similar to coral reefs and may therefore offer exciting opportunities for studying the ecology and evolution of chemical defenses in this unique system.

Although our understanding of genetic and phenotypic biodiversity in the sea is very limited (Knowlton et al., 1992; Knowlton, 1993; Norse, 1993), recent studies demonstrate that benthic organisms can show dramatic between-site differences in their production of secondary metabolites (Pettit, 1991; Harvell et al., 1993; Bolser and Hay, in press; Cronin and Hay, in press). Some of this variance is environmentally induced rather than genetic (Cronin and Hay, 1996b), but there is 
clear potential for genetic variance as well. Present conservation efforts run the risk of losing this intraspecific biodiversity if they focus on preserving species without an adequate appreciation for the genetic and phenotypic diversity that occur within a species. In the case of the bryozoan Bugula neritina, a promising anti-cancer agent could have been lost if the species, but not the particular populations that produce bryostatin 1 (Fig. 1) had been preserved. Because we understand so little about intraspecific variation in the production of marine secondary metabolites, wise and efficient conservation of biodiversity at this level is presently impossible. If this largely undocumented intraspecific biodiversity is to be preserved, then conservation efforts will have to be general. broad, and based on the assumption that nature, its variance, and the products and services derived therefrom are inherently valuable. Conservation efforts based on this ethic will be a challenge in societies and political systems that seek to maximize gain rather than minimize loss.

\section{Acknowledgements}

Our investigations would have been impossible without sustained support from the National Science Foundation through combined efforts of the Ocean Sciences and Chemistry Divisions. Comments from Robin Bolser. Niels Lindquist, Sarah Johnson, and an anonymous reviewer improved the manuscript.

\section{References}

Attaway. D.H. and O.R. Zaborsky, eds.. 1993: Marine Biotechnology. vol. I, Pharmaceutical and Bioactive Natural Products. Plenum Press, New York

Barrie, L.A., J.W. Bottenheim. R.C. Schnell. P.J. Cruzten and R.A. Rasmussen, 1988: Ozone destruction and phytochemical reactions at sunrise in the lower Arctic atmosphere. Nature, 334, 138-141.

Bolser. R.C. and M.E. Hay, in press: Are tropical plants better defended? Palatability and defenses of temperate versus tropical seaweeds. Ecology:

Carpenter, R.C.. 1986: Partitioning herbivory and its effects on coral reef algal communities. Ecol. Monogr.. 56, 34.5-363.

Cronin, G. and M.E. Hay, 1996a: Within-plant variation in seaweed palatability and chemical defenses: optimal defense theory versus the growth-differentiation balance hypothesis. Oecologia, 105, 361-368.

and M.E. Hay, 1996b: Susceptibility to herbivores de pends on recent history of both the plant and animal. Ecology. 77 (in press)

and M.E. Hay, in press: Induction of seaweed chemical defenses by amphipod grazing. Ecology.

Dayton, P.K.. 1985: The structure and regulation of some South American kelp communities. Ecol. Monogr., 55, 447-468.

Duffy, J.E. and M.E. Hay. 1994: Herbivore resistance to seaweed chemical defense: the roles of herbivore mobility and predation risk. Ecology, 75, 1304-1319.

Duggins, D.O., C.A. Simenstad and J.A. Estes, 1989: Magnification of secondary production by kelp detritus in coastal marine ecosystems. Science, 245, 170-173.

Ehrlich, P.R. and J. Roughgarden, 1987: The Science of Ecology. Macmillan Publishing. New York. $710 \mathrm{pp}$.

Faulkner, D.J., 1994: Marine natural products. Nat. Prod. Rep.,
II. 355-394.

Fautin, D.G., ed., 1988: The Biomedical Importance of Marine Organisms. Memoirs of the California Academy of Sciences \#13. California Academy of Sciences, San Francisco.

Fenical, W., 1993: Chemical studies of marine bacteria: developing a new resource. Chem. Rev.. 93, 1673-1683.

Gil-Turnes, M.S., M.E. Hay and W. Fenical, 1989: Symbiotic marine bacteria chemically defend crustacean embryos from a pathogenic fungus. Science, 246, 116-118.

Harvell, C.D., W. Fenical, V. Roussis, J.L. Ruesink, C.C. Griggs and C.H. Green, 1993: Local and geographic variation in the defensive chemistry of a West Indian gorgonian coral (Briareum asbestinum). Mar. Ecol. Prog. Ser., 93, 165-173.

Hay, M.E.. 1986: Associational plant defenses and the maintenance of species diversity: turning competitors into accomplices. Am. Nat., 128, 617-641.

1991: Marine-terrestrial contrasts in the ecology of plant chemical defenses against herbivores. Trends Ecol. Evol., 6, 362-365.

1992: The role of seaweed chemical defenses in the evolution of feeding specialization and in the mediation of complex interactions. In: Ecological Roles for Marine Natural Products, V.J. Paul, ed., Comstock Press, Ithaca, 93-118.

J.E. Duffy and W. Fenical, 1990: Host-plant specialization decreases predation on a marine amphipod: an herbivore in plant's clothing. Ecology, 7I, 733-743.

and W. Fenical, 1988: Marine plant-herbivore interactions: the ecology of chemical defense. Annu. Rev. Ecol. Syst. 19. 111-145.

J.R. Pawlik. J.E. Duffy and W. Fenical. 1989: Seaweed-herbivore-predator interactions: host-plant specialization reduces predation on small herbivores. Oecologia, 81, 418-427

and P.D. Steinberg, 1992: The chemical ecology of plant-herbivore interactions in marine versus terrestrial communities. In: Herbivores: Their Interaction with Secondary Metabolites, Evolutionary and Ecological Processes. J. Rosenthal and M. Berenbaum, eds., Academic Press, San Diego, 371-413.

Hughes, T.P., 1994: Catastrophes, phase shifts, and large-scale degradation of a coral reef. Science, 265, 1547-1551.

Huntley, M.. P. Sykes, S. Rohan and V. Martin, 1986: Chemically-mediated rejection of dinoflagellate prey by the copepods Calanus pacificus and Paracalanus parvus: mechanism, occurrence and significance. Mar. Ecol. Prog. Ser., 28, 105-120.

Jones, A., 1994: The pharma-sea. Financial World. 163, $24-29$.

Knowlton, N., 1993: Sibling species in the sea. Annu. Rev. Ecol. Syst. 24, 189-216.

E. Weil, L.A. Weigt and H.M. Guzmán, 1992: Sibling species in Montastraea annularis, coral bleaching, and the coral climate record. Science. 255, 330-333.

Kvitek, R.G.. A.R. DeGange and M.K. Beitler, 1991: Paralytic shellfish poisoning toxins mediate feeding behavior of sea otters. Limnol. Oceanogr., 36, 393-404.

Littler, M.M., P.R. Taylor and D.S. Littler, 1986: Plant defense associations in the marine environment. Coral Reefs. 5 . $63-71$.

Look. S.A., W. Fenical, R.S. Jacobs and J. Clardy, 1986: The pseudopterosins: Anti-inflammatory and analgesic natural products from the sea whip Pseudopterogorgia elisabethae. Proc. Natl. Acad. Sci. USA, 83, 6238-6240.

McClintock. J.B.. 1994: An Overview of the Chemical Ecology of Antarctic Marine Invertebrates. The Ireland Lecture 1993. University of Alabama, Birmingham. $24 \mathrm{pp}$.

Meyers, R.A., L.J. Cruz, J.E. Rivier and B.M. Olivera, 1993: Conus peptides as chemical probes for receptors and ion channels. Chem. Rev. 93, 1923-1936.

Norse. E.A.. ed.. 1993: Global Marine Biological Diversity: A Strutegy for Building Decision into Decision Making.
C

onservation efforts

based on this ethic

will be a challenge in

societies and political

systems that seek to

maximize gain rather

than minimize loss. 
Island Press, Washington. DC, $383 \mathrm{pp}$.

Paerl. H.W.. 1988: Nuisance phytoplankton blooms in coastal, estuarine, and inland waters. Limnol. Oceanogr. 33, 823-847.

Paul, V.J.. ed.. 1992: Ecological Roles for Marine Natural Products, Comstock Publishing Associates, Ithaca, 245 pp.

Pawlik, J.R., 1993: Marine invertebrate chemical defenses. Chem. Rev.. 93, 1911-1922.

Pettit, G.R.. 1991: The bryostatins. Prog. Chem. Organic Natural Products. 57, 153-195.

Pfister. C.A. and M.E. Hay. 1988: Associational plant refuges: convergent patterns in marine and terrestrial communities result from differing mechanisms. Oecologia, 77. $118-129$.

Potts. B.C.M.. D.J. Faulkner, M.S. de Carralho and R.S. Jacobs, 1992: Chemical mechanism of inactivation of bee venom phospholipase $\mathrm{A}_{2}$ by the marine natural products manolide, luffariellolide, and scalaradial. J. Am. Chem. Soc.. 114, 5093-5100.

Simenstad. C.A.. J.A. Estes and K.W. Kenyon. 1978: Aleuts. sea otters, and alternate stable-state communities. $S c i-$ ence. 200, 403-411.

Steinberg, P.D., 1992: Geographical variation in the interaction between marine herbivores and brown algal secondary metabolites. In: Ecological Roles for Marine Natural Products. V.J. Paul, ed., Comstock Press. Ithaca. 51-92.

Strong. D.R.. J.H. Lawton and R. Southwood. 1984: Insects on Plants: Community Patterns and Mechanisms. Harvard University Press, Cambridge, $313 \mathrm{pp}$.

Takahashi, T., 1979: Modulation of berve membrane sodium channels by neurotoxins. In: Advances in Cytopharmacology, wol. 3. B. Ceccarelli and F. Clementi, eds. Raven Press, New York, 293-304.

Tegner. M.J. and P.K. Dayton, 1987: El Niño effects on southen California kelp forest communities. Adv: Ecol. Res. 17. 243-279.

Toske, S.G. and W. Fenical. 1995: Cyclodidemnamide: a new cyclic heptapeptide from the marine ascidian Didemnum molle. Tetrahedron Lett. 36, 8355-8358.

Unson, M. and D.J. Faulkner, 1993: Cyanobacterial symbiont biosynthesis of chlorinated metabolites from Dysidea herbaceae (Porifera). Experientia, 49, 349-353.

Wahl, M. and M.E. Hay, 1995: Associational resistance and shared doom: effects of epibiosis on herbivory. Oecologia, 102, 329-340.

Weaver, R., 1988: Ozone destruction by algae in the Arctic atmosphere. Nature. 335, 501 . 